\title{
https://tecnohumanismo.online
}

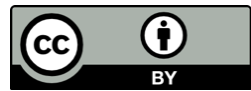

\section{Los Contratos Inteligentes (Smart-Contracts) en el alquiler tradicional de viviendas en Lima Metropolitana}

Intelligent Contracts (Smart-Contracts) in the traditional rental of housing in Metropolitan Lima Contratos Inteligentes (Smart-Contracts) no aluguel tradicional de moradias na área metropolitana de Lima

\section{ARTÍCULO GENERAL}

\author{
César Loo Gil \\ https://orcid.org/0000-0001-8396-5972 \\ cesarloo@biofab.com.pe \\ Científico Investigador de BioFab Inc, Lima -Perú
}

Recibido 10 de Enero 2020 | Arbitrado y aceptado 06 de Febrero 2021 | Publicado el 01 de Abril 2021

\section{RESUMEN}

Aunque América Latina y el Caribe es una región en la que prevalecen los propietarios, el alquiler continúa siendo significativo, tan es así que uno de cada cinco hogares alquila su vivienda. Esta cifra ha ido en aumento durante las últimas décadas en la mayoría de países de la mencionada región: Argentina pasó de un millón en 1980 a 1,8 millones en 2010; Brasil de 5,7 millones en 1990 a 10,5 millones en 2010; Chile de 640 mil en 1982 a 917 mil en 2002; Colombia de 1,2 millones en 1985 a 2,8 millones en 2005; México de 2,5 millones en 1980 a 4 millones en 2010, y Perú de 481 mil en 1981 a 980 mil en 2007 (Blanco, Fretes y Muñoz, 2014). Al comparar esta cifra con los resultados obtenidos del último Censo llevado a cabo en 2017, se observa en nuestro país un incremento de 40 mil 27 viviendas más que están en alquiler o venta (INEI, 2018). Estos datos se perciben aún más presentes en algunos de los grupos de población que están en crecimiento como jóvenes, divorciados, adultos mayores y hogares unipersonales, lo que sugiere que se debe apoyar el alquiler para satisfacer mejor las preferencias de la demanda y crear, además, mayor movilidad laboral y residencial (Uniapravi, 2016).

\section{ABSTRACT}

Although Latin America and the Caribbean is a region in which owners prevail, rents continue to be significant, so much so that one in five households rents their home. This figure has been increasing during the last decades in most of the countries of the aforementioned region: Argentina went from one million in 1980 to 1.8 million in 2010; Brazil from 5.7 million in 1990 to 10.5 million in 2010; Chile from 640 thousand in 1982 to 917 thousand in 2002; Colombia from 1.2 million in 1985 to 2.8 million in 2005; Mexico from 2.5 million in 1980 to 4 million in 2010, and Peru from 481 thousand in 1981 to 980 thousand in 2007 (Blanco, Fretes and Muñoz, 2014). When comparing this figure with the results obtained from the last Census carried out in 2017, an increase of 40 thousand 27 more homes that are for rent or sale is observed in our country (INEI, 2018). These data are perceived to be even more present in some of the population groups that are growing, such as young people, the divorced, the elderly and single-person households, which suggests that renting should be supported to better satisfy demand preferences and create, in addition, greater labor and residential mobility (Uniapravi, 2016).

\section{RESUMO}

Embora a América Latina e o Caribe sejam uma região onde predominam os proprietários, os aluguéis continuam sendo significativos, tanto que um em cada cinco domicílios aluga sua casa. Esta cifra vem aumentando nas últimas décadas na maioria dos países da referida região: a Argentina passou de um milhão em 1980 para 1,8 milhão em 2010; Brasil de 5,7 milhões em 1990 para 10,5 milhões em 2010; Chile de 640 mil em 1982 para 917 mil em 2002; Colômbia de 1,2 milhões em 1985 para 2,8 milhões em 2005; México de 2,5 milhões em 1980 para 4 milhões em 2010, e Peru de 481 mil em 1981 para 980 mil em 2007 (Blanco, Fretes e Muñoz, 2014). Ao comparar este valor com os resultados obtidos no último Censo realizado em 2017, verifica-se um aumento de $40 \mathrm{mil}$ mais 27 casas que se encontram para arrendamento ou venda no nosso país (INEI, 2018). Estes dados são percebidos como ainda mais presentes em alguns dos grupos populacionais em crescimento, como os jovens, os divorciados, os idosos e os agregados familiares unipessoais, o que sugere que o arrendamento deve ser apoiado para melhor satisfazer as preferências da procura e criar, além disso, maior mobilidade laboral e residencial (Uniapravi, 2016). 


\section{Introducción}

\section{Variable: alquiler tradicional de vivienda}

Aunque América Latina y el Caribe es una región en la que prevalecen los propietarios, el alquiler continúa siendo significativo, tan es así que uno de cada cinco hogares alquila su vivienda. Esta cifra ha ido en aumento durante las últimas décadas en la mayoría de países de la mencionada región: Argentina pasó de un millón en 1980 a 1,8 millones en 2010; Brasil de 5,7 millones en 1990 a 10,5 millones en 2010; Chile de 640 mil en 1982 a 917 mil en 2002; Colombia de 1,2 millones en 1985 a 2,8 millones en 2005; México de 2,5 millones en 1980 a 4 millones en 2010, y Perú de 481 mil en 1981 a 980 mil en 2007 (Blanco, Fretes y Muñoz, 2014). Al comparar esta cifra con los resultados obtenidos del último Censo llevado a cabo en 2017, se observa en nuestro país un incremento de 40 mil 27 viviendas más que están en alquiler o venta (INEI, 2018). Estos datos se perciben aún más presentes en algunos de los grupos de población que están en crecimiento como jóvenes, divorciados, adultos mayores y hogares unipersonales, lo que sugiere que se debe apoyar el alquiler para satisfacer mejor las preferencias de la demanda y crear, además, mayor movilidad laboral y residencial (Uniapravi, 2016).

Según Blanco et al. (2014) en los países de mayor tamaño de la región Argentina, Brasil, Chile, Colombia, México y Perú - las variables sociales como edad, tipo y tamaño del hogar, estado civil y tipo de empleo, influencian significativamente en la probabilidad de que un hogar elija alquilar frente a la opción de convertirse en propietario. Y, cabe mencionar que, a diferencia de lo que ocurre en países más desarrollados, en Argentina, Chile y Perú la probabilidad de alquilar versus ser propietario se incrementa a medida que el ingreso es más alto.

El alquiler presenta muchos beneficios en comparación a la vivienda sin título e incluso frente a la que sí tiene título en términos de flexibilidad, centralidad, y calidad, este último en relación a la infraestructura, materiales y hacinamiento. En ese sentido, las viviendas de alquiler suelen tener mejores conexiones a agua potable, saneamiento y electricidad, asimismo, menor prevalencia de techos y paredes de materiales no 
permanentes y menor prevalencia hacinamiento (Uniapravi, 2016). No obstante, el alquiler también presenta riesgos y costos y no solo aquellos que guardan relación con catástrofres naturales, regulaciones del uso del suelo, ciclos económicos o la depreciación física del inmueble, sino que este mercado conlleva a otro tipo de problemas como son la probabilidad de vacancia, deterioro por el mal uso, y uno de los más alarmantes, falta de pago por parte del inquilino y la incertidumbre del proceso de reposeción (Blanco et al., 2014).

\section{Variable: smart-contracts}

Teniendo como contexto la incorporación de las Tecnologías de la Información y Comunicación (TIC) en la vida cotidiana del ser humano cada vez con más fuerza, era evidente la evolución de procesos estandarizados como los contratos tradicionales hacia lo digital. En ese sentido, los contratos inteligentes o smart contract, hacen referencia a todo tipo de contratos que se lleven a cabo de forma automática sin la necesidad de un tercero entre los participantes individuales. Estos se escriben como programas informáticos en vez de usar un lenguaje legal sobre un documento impreso como solía hacerse tradicionalmente. Este concepto fue acuñado por Nick Szabo en 1994, no obstante debido a la carencia de una infraestructura tecnológica en la que apoyarse, no se concretó y es hasta la actualidad con la llegada del blockchain, o cadena de bloques, que esta situación se revierte y la idea cobra vida (BBVA, 2015).

En ese sentido, en nuestro país, el proceso de normatización de contratos electrónicos lleva gestionándose desde hace algunos años y a nivel legal se ampara en leyes y algunas de las más representativas son: La Ley 27291 que indica la permisión de la manifestación de la voluntad a través de medios electrónicos y la Ley 27269 que regula el uso de firma electrónica y el funcionamiento de entidades de certificación (Hernández, 2012).

Cabe mencionar que, aunque los contratos electrónicos son flexibles y varían de acuerdo a la necesidad de las partes, la mayoría se rige por cinco principios básicos, estos son: Principio de Equivalencia Funcional, este se refiere a la paridad, identidad o correspondencia de las instituciones jurídicas del mundo material a las concebidas en el contexto digital, velando para que se cumpla con las finalidades y objetivos de la figura; el Principio de Neutralidad Tecnológica que señala que los marcos regulatorios del 
comercio y contratación electrónica no deben excluir o privilegiar una técnica o tecnología en específico; el Principio de la Inalterabilidad del Derecho Vigente reza que la reglamentación sobre el contrato celebrado con ayuda de medios electrónicos no modifica, altera ni deroga las normas sobre la existencia, validez, ejecución, cumplimiento o incumplimiento del contrato en sí mismo; el Principio de la Autonomía de la Voluntad Privada refiere al atributo que la ley les confiere a las manifestaciones de voluntad de los particulares, para que regulen su vida en sociedad; Principios de Consensualidad, esencial para los negocios mercantiles, indica que el contrato se perfecciona por acuerdo de las voluntades de las partes y desde el instante en que se presta (Hernández, 2012).

Como hemos mencionado anteriormente, los smart contract no son un concepto nuevo en cuanto a la teoría, no obstante fue con la cuarta revolución industrial que incorpora la inteligencia artificial (donde reside el blockchain) que se le da una aplicabilidad. Los contratos inteligentes empezaron a usarse hace no más de cuatro años con la creación de Ethereum, una plataforma global de código abierto para aplicaciones descentralizadas. La definición de los contratos inteligentes reside, entonces, en un programa informático que realiza acuerdos entre dos o más partes contratantes donde se ejecutan autónoma y automáticamente los términos de un contrato; el programa puede definir las reglas y las consecuencias estrictas del mismo, de la misma manera que lo haría un contrato tradicional, pero con la diferencia que también puede obtener información como entrada y procesarla según las condiciones establecidas previamente en el contrato para adoptar las medidas que se requieran como consecuencia de ello. Además, se debe tomar en cuenta que en estos, la oferta y aceptación se da mediante una comunicación a través de medios electrónicos sin necesidad de la presencia física dado que el objetivo es erradicar las barreras de tiempo y territorio. Los contratos electrónicos están estrechamente relacionados con las páginas web y aplicaciones (Valencia, 2019).

\section{Bibliografía}

BBVA (2015) Smart Contracts: ¿Lo último en automatización de la confianza? Situación Economía Digital. 4-17. 
Blanco, A., Fretes, V. y Muñoz, A. (2014) Se busca vivienda en alquiler: Opciones de política en América Latina y el Caribe. Washington D.C, Estados Unidos. Banco Interamericano de Desarrollo

Hernández, W. (2012) La formación del contrato a través de medios electrónicos en el marco de la Comunidad Andina. Bogotá, Colombia. Universidad Sergio Arboleda.

INEI (2018) Perú: Características de las viviendas particulares y los hogares. Acceso a servicios básicos. Lima, Perú. Instituto Nacional de Estadística e InformáticaINEI.

UNIAPRAVI (2016) Vivienda en alquiler: retos y oportunidades para atender la demanda de vivienda. VI Foro Interamericano de Ciudad y Financiamiento Habitacional organizado por: Unión Interamericana para la Vivienda (UNIAPRAVI) Ministerio de Vivienda, Construcción y Saneamiento (MVCS) y Fondo MIVIVIENDA S.A.

Valencia, J. (2019) Contratos inteligentes. Revista de Investigación en Tecnologías de la Investigación. 7. 1-10. 